\title{
Relationship Between Postoperative Lordosis Distribution Index And Adjacent Segment Disease Following L4-S1 Posterior Lumbar Interbody Fusion
}

\section{Guoquan Zheng}

Chinese PLA General Hospital

Chunguo Wang

Chinese PLA General Hospital

\section{Tianhao Wang}

Chinese PLA General Hospital

Wenhao Hu

Chinese PLA General Hospital

\section{Quanbo Ji}

Chinese PLA General Hospital

\section{Fanqi Hu}

Chinese PLA General Hospital

Jianrui Li

Tongji University school of medicine

Surendra K Chaudhary

Tongji University School of Medicine

Kai Song

Chinese PLA General Hospital

\section{Diyu Song}

Chinese PLA General Hospital

\section{Zhifa Zhang}

Chinese PLA General Hospital

\section{Yongyu Hao}

Chinese PLA General Hospital

\section{Yao Wang}

Chinese PLA General Hospital

Jing Li

Chinese PLA General Hospital

Qingyuan Zheng

Chinese PLA General Hospital

Xuesong Zhang 
Chinese PLA General Hospital

\section{Yan Wang ( D Derekwangyan@126.com )}

Chinese PLA General Hospital https://orcid.org/0000-0001-5422-9212

\section{Research article}

Keywords: Adjacent segment disease, posterior lumbar interbody fusion, lordosis distribution index, lower lumbar lordosis, lumbar lordosis

Posted Date: January 13th, 2020

DOI: https://doi.org/10.21203/rs.2.20711/v1

License: (9) This work is licensed under a Creative Commons Attribution 4.0 International License. Read Full License

Version of Record: A version of this preprint was published at Journal of Orthopaedic Surgery and Research on April 3rd, 2020. See the published version at https://doi.org/10.1186/s13018-020-01630-9. 


\section{Abstract}

Background. ASD is an acknowledged problem of PLIF. Many studies have been reported concerning the role of LDI in spinal biomechanics. However, few reports have been published about the impact of LDI on ASD following L4-S1 PLIF.

Methods. The study enrolled 200 subjects who underwent L4-S1 PLIF for degenerative spine disease from 2009 to 2014. The average follow-up term was 84 months. Several lower lumbar parameters were measured, including lower lumbar lordosis (LLL), lumbar lordosis (LL) and LDI on the pre-and postoperative radiograph. Perioperative information, comorbidities and operative data were documented. Kaplan-Meier curves were plotted for the comparisons of ASD-free survival of 3 different kinds of postoperative LDI subgroups.

Results. The incidence of ASD was found to be $8.5 \%$. LL and LLL increased by $3.96^{\circ}\left(38.71^{\circ}\right.$ vs $42.67^{\circ}$, $P \otimes 0.001)$ and $3.60^{\circ}\left(26.22^{\circ}\right.$ vs $\left.28.82^{\circ}, P \otimes 0.001\right)$ after lower lumbar fusion surgery, respectively. Lordosis distribution index (LDI) increased by 0.03 ( 0.66 vs $0.69, \mathrm{P}=0.004)$ postoperatively. A significant difference $(P=0.001)$ was observed when comparing the incidence of ASD among postoperative LDI subgroups. The Kaplan-Meier curves showed a marked difference in ASD-free survival between low and moderate LDI subgroup (Log Rank test, $\mathrm{P}=0.0012$ ) , high and moderate LDI subgroup (Log Rank test, $\mathrm{P}=0.0005)$

Conclusion. Patients with abnormal postoperative LDI were statistically more likely to develop ASD than those who had normal postoperative LDI. Moreover, patients with low postoperative LDI were at greater risk for developing ASD than those with high postoperative LDI over time.

\section{Introduction}

Posterior lumbar interbody fusion (PLIF) with pedicle screw fixation has been widely accepted to treat various lumbar spinal disorders involving lumbar spinal stenosis, lumbar disc herniation, degenerative spinal deformity, instability, spondylolisthesis and vertebral compression fracture. Although PLIF with pedicle screw fixation could provide solid instrumentation and achieve satisfactory clinical effects, it may alter the normal biomechanics of the spine and accelerate the degenerative process of adjacent unfused segments, resulting in adjacent segment disease. ${ }^{1-6}$ Adjacent segment disease (ASD) is one of the widely acknowledged problems of posterior lumbar interbody fusion which encompasses many complications, including herniated nucleus pulposus, spondylolisthesis, stenosis, hypertrophic facet arthritis and scoliosis. ${ }^{5,7,8}$

Various studies have proposed the risk factors for the development of ASD after lumbar spinal fusion, including age, sex ,obesity, body mass index(BMI),fusion length, osteoporosis, laminectomy performed adjacent to a segment, preoperative segmental instability at the adjacent level, preexisting degenerated disc prior to fusion and excessive disk height distraction. ${ }^{9-12}$ In addition, lower lumbar interbody fusion 
surgeries constitute the main part of the spinal surgeries in a spine surgeon's clinical work. ${ }^{13}$ The total lumbar lordosis mainly consists of the upper-arc lordosis of L1-L3 and lower-arc lordosis of L4-S1. Lower lumbar lordosis(LLL), defined as the angle between the superior endplate of $L 4$ and $S 1$, accounts for two thirds of the total lumbar lordosis. ${ }^{14,15}$ Lordosis distribution index (LDI), described as L4-S1 lordosis/L1S1 lordosis $\times 100 \%$, defines the magnitude of lower-arc lordosis relative to the total lordosis. ${ }^{16}$ Few studies have shown the impact of LDI on ASD after lower lumbar spine surgery. Therefore, it is critical to explore the factors to reduce the incidence of ASD in patients performed lower lumbar spine.

The aim of this study is to examine the association of postoperative LDI with ASD following L4-S1 posterior lumbar interbody fusion with pedicle screw fixation for spinal degenerative diseases, and provide guidance in surgical planning for a spine surgeon to improve patients' outcome and further alleviate medical costs.

\section{Materials And Methods}

\section{Subjects and Surgical Procedure}

This is a retrospective study, including a total of 215 consecutive patients who were treated for spinal degenerative pathologies at the Chinese PLA General Hospital over a 5-year period from 2009 to 2014. The protocol was approved by the research ethics committee of the hospital. The patients were enrolled to meet the following inclusion criteria: degenerative disorders of lower lumbar spine such as lumbar disc herniation and symptomatic lumbar spinal stenosis with severe lower back pain and radiculopathy. All the subjects were performed with L4-S1 PLIF and bilateral lumbar laminectomy of vertebrae L4-5 using an PEEK cage inserted to intervertebral space. The cage was placed after the disk space was cleaned and the autograft bones crumbled from resected lamina were put into the space. The minimum follow-up period was 19 months with imaging collection including lumbar plain anteroposterior and lateral X-ray obtained before surgery, immediately following surgery. CT and MRI scans were obtained before surgery, the instant a new onset of symptoms appeared and at the final follow-up visit. We excluded patients who were diagnosed as spinal neoplasm, trauma, hip joint disease, infection, compression fracture of vertebra, inflammation, rheumatoid arthritis and isthmic spondylolisthesis. Subjects who had scoliosis with a Cobb angle $\geq 10^{\circ}$, previous lumbar fusion or laminectomy surgeries, preoperative spondylolisthesis $\geq 3$ $\mathrm{mm}$ at the adjacent level and severe adjacent intervertebral disc degeneration of Pfirrmann Classification $\checkmark$ were also excluded from this study. ${ }^{17}$ Therefore, 200 patients (89 men and 111 women) were enrolled in this study with a mean age of $64.8 \pm 8.5$ years (range, 36 years to 85 years). The average follow-up term was 84 months $\left(\mathrm{P}_{25} \llbracket \mathrm{P}_{75}, 70 \otimes 98\right.$ months).

Adjacent segment disease (ASD) is defined as a pathologic condition seen on radiographs with clinical symptoms in which an additional surgical intervention may be required to treat neurological symptoms at the level adjacent to previous fusion. ${ }^{18}$ The radiographic ASD was defined by segmental kyphosis more than $10^{\circ}$, the development of anterolisthesis or retrolisthesis of more than $3 \mathrm{~mm}$ and a deterioration in the Pfirrmann classification(grades I-V) or Imagama's Classification (grades I-IV) of one-grade or greater 
progression at the level adjacent to a previous spinal fusion. ${ }^{19-21}$ The clinical ASD is considered to be adjacent disc degeneration leading to newly developed symptoms, such as stenosis, instability and neurological abnormality. ${ }^{22}$

\section{Radiographic Evaluation and Clinical Data Collection}

Lumbar lordosis(LL) is defined by the angle between the superior endplate of L-1 and S-1 on the neutral lateral X-ray image. Lower lumbar lordosis(LLL) is measured from the superior endplate of $L 4$ to the superior endplate of $\mathrm{S} 1$ by the Cobb method on lumbar plain lateral X-ray. Lordosis distribution index $($ LDI) is represented by the following formula: lower lumbar lordosis/lumbar lordosis $\times 100 \%$ (Figure 1 ). All measurements were performed 2 times by a trained spine surgeon blinded to clinical outcomes with the aid of Surgimap (version 2.3), and the mean values were recorded for the analysis. LDI is divided into 3 subgroups. An LDI less than $50 \%$ is considered hypolordotic maldistribution (low LDI); $50 \%-80 \%$, aligned (moderate LDI); and more than $80 \%$, hyperlordotic maldistribution (high LDI). ${ }^{16}$ Perioperative information including demographic variables, comorbidities and operative data.

\section{Statistical Analysis}

Continuous variables are presented as meanstandard deviation or $\mathrm{P}_{50}\left(\mathrm{P}_{25} \otimes \mathrm{P}_{75}\right)$ according to ShapiroWilk normality tests. SPSS (version 23) for windows was performed for statistical analysis. The Pearson $\chi 2$ test or Fisher's exact test was used for the comparison of sex, BMI intergroup, comorbidities, pre and postoperative LDI subgroup between ASD and Non-ASD group. The nonparametric test of Mann-Whitney $\mathrm{U}$ test was applied for follow-up period, intraoperative blood loss, operation time and hospital stay. The independent-samples $t$ test was used for radiographic parameters of the lumbar spine. The pairedsamples $t$ test was used to compare pre and postoperative changes in the lower lumbar parameters. Kaplan-Meier curves were plotted and compared by the use of log-rank tests. An a level of 0.05 was considered to be statistically significant.

\section{Results}

\section{Subjects and Surgical Procedure}

Adjacent segment disease (ASD) after L4-S1 PLIF for degenerative disease of lower lumbar spine was developed in 17 of 200 patients (8.5\%) at the final follow-up. Segment lesions of them were identified at the level above the fusion and all of them were enrolled in the ASD group. In the ASD group, 6 male and 10 female subjects were included, with an average age of $66.1 \pm 5.1$. The mean follow-up period was $62.8 \pm 24.6$ months. BMI at admission was $27.04 \pm 3.00 \mathrm{~kg} / \mathrm{m}^{2}$ at average. In the Non-ASD group, 82 male and 101 female subjects were included, with an average age of $64.7 \pm 8.7$.The average follow-up duration 
was 85 months (72 months $₫ 99$ months). BMI at admission was $23.87 \pm 3.33 \mathrm{~kg} / \mathrm{m}^{2}$ at average. 101 patients had $B M I \geq 25 \mathrm{~kg} / \mathrm{m}^{2}, 13$ patients (12.87\%) of which finally developed ASD. 121 patients had BMIX $25 \mathrm{~kg} / \mathrm{m}^{2}, 4$ patients (3.31\%) of which were diagnosed as having ASD in the end. Table 1 show the comparisons of basic characteristics of patients between ASD and Non-ASD group. Statistical analysis identified the significant difference in BMI (23.87 vs 27.04 , p $₫ 0.001)$, BMI intergroup ( $23.5 \%$ vs $76.5 \%$, $\mathrm{P}=0.001$ ) and the average follow-up period ( 85.0 vs $62.8, P \llbracket 0.001$ ). But there was no statistically significant difference between the two groups in such basic variables as age, sex, comorbidities, hospital stay, intraoperative blood loss and operation time. Figure 2 illustrates the frequency distribution of followup time of ASD patients after L4-S1 PLIF.

\section{Radiographic Evaluation and Clinical Data Collection}

In the radiographic evaluation, measured lower lumbar spinal parameters using pre and postoperative radiographs are shown in table $2 . L L$ and LLL increased by $3.96^{\circ}\left(38.71^{\circ}\right.$ vs $\left.42.67^{\circ}, P \otimes 0.001\right)$ and $3.60^{\circ}\left(26.22^{\circ}\right.$ vs $\left.28.82^{\circ}, \mathrm{P} \otimes 0.001\right)$ after lower lumbar fusion surgery, respectively. Moreover, LDI increased by 0.03 ( 0.66 vs $0.69, \mathrm{P}=0.004)$ postoperatively. Table 3 demonstrates the comparisons of lower lumbar spinal parameters and LDI with and without ASD groups. There was no statistical significance in radiographic parameters of pre $\operatorname{LL}\left(37.17^{\circ}\right.$ vs $\left.38.85^{\circ}, P=0.341\right)$, pre $\operatorname{LLL}\left(23.71^{\circ}\right.$ vs $\left.26.36^{\circ}, P=0.177\right)$, the value of pre $\operatorname{LDI}(0.65$ vs $0.66, P=0.682)$, post $L L\left(40.35^{\circ}\right.$ vs $\left.42.88^{\circ}, P=0.241\right)$, post $L L L\left(27.69^{\circ}\right.$ vs $\left.28.93^{\circ}, P=0.410\right)$, and the value of post $L D I(0.71$ vs $0.68, P=0.578)$. When comparing pre and postoperative LDI subgroups between ASD and Non-ASD groups, the patients with low LDI pre and postoperatively in the ASD group was $2(11.8 \%)$ and 4 (23.5\%), respectively. The patients with moderate LDI pre and postoperatively in the ASD group was $13(76.4 \%)$ and $6(35.3 \%)$, respectively. The patients with high LDI pre and postoperatively in the ASD group was 2 (11.8\%) and 7 (41.2\%), respectively. Consequently, significant difference was found in the postoperative LDI subgroups $(P=0.001)$ but none in the preoperative $L D I$ subgroups $(P=0.252)$.

\section{Relationship Between Postoperative LDI and ASD}

With respect to the abnormal range of LDI that could be associated with the development of ASD, we attempted to integrate the low LDI subgroup and the high LDI subgroup into a single group named abnormal LDI intergroup. The patients with normal LDI pre and postoperatively in the ASD group was 13 (76.5\%) and $6(35.3 \%)$, respectively. The patients with abnormal LDI pre and postoperatively in the ASD group was $4(23.5 \%)$ and $11(64.7 \%)$, respectively. Statistical analysis revealed a significant difference between normal and abnormal LDI intergroup postoperatively $(P=0.001)$, but none was found in the preoperative status $(P=0.267)$. A typical case is presented in figure 3 . When comparing the incidence of ASD among different postoperative LDI subgroups, we find statistical significance between low and 
moderate LDI subgroup ( $25 \%$ vs $4.1 \%, P=0.006)$, high and moderate LDI subgroup ( $18.4 \%$ vs $4.1 \%$, $P=0.007)$ but none was observed between low and high LDI subgroup ( $25 \%$ vs $18.4 \%, P=0.859)$ (table 4 ).

Kaplan-Meier analysis survivorship by LDI subgroups was performed to assess the rate of Non-ASD survival for ASD in patients undergoing L4-S1 PLIF (Figure 4). In low LDI subgroup, ASD-free survival was estimated to be $87.5 \%$ at 3 years and $75.0 \%$ at 6 years. In moderate LDI subgroup, ASD-free survival was estimated to be $99.3 \%$ at 3 years and $97.6 \%$ at 6 years. In high LDI subgroup, ASD-free survival was estimated to be $97.4 \%$ at 3 years and $84.5 \%$ at 6 years. The Kaplan-Meier curves showed a marked difference in ASD-free survival among the three kinds of LDI subgroups (Log Rank test, $P=0.001$ ). When comparing survival proportions of every two kinds of LDI groups, we found that the survival rate differ significantly between low and moderate LDI subgroup (Log Rank test, $\mathrm{P}=0.0012$ ), high and moderate LDI subgroup (Log Rank test, $P=0.0005$ ). However, no statistical significance was observed between low and high LDI subgroup(Log Rank test, $\mathrm{P}=0.7223$ ).

\section{Discussion}

Adjacent segment disease (ASD) is a thorny sequelae after posterior lumbar interbody fusion for spinal degenerative diseases. ${ }^{1-8}$ Many studies have reported mechanisms concerning the cause of ASD. However, the specific pathogenesis of ASD is still unknown. Liuke et al ${ }^{23}$ revealed the fact that $B M I \geq$ $25 \mathrm{~kg} / \mathrm{m}^{2}$ increases the risk of lumbar disc degeneration. Bagheri et al ${ }^{24}$ demonstrated that patients with higher preoperative BMI have a statistically significant increased risk of developing ASD. Our results were consistent with the previous studies. Normal aging and degenerative process could partially accelerate the progression of ASD. Patient age at the time of the index surgery has been identified as one of the most important risk factors for ASD. Several studies have shown that the incidence of ASD tends to be higher according to advancing age. ${ }^{21,25}$ But no statistical relationship was observed between advancing age and ASD in our study. The reported incidence of ASD varies widely, ranging from $5.2-18.5 \% .{ }^{4} \mathrm{We}$ reported a cumulative ASD incidence of $8.5 \%$. In this series, we defined ASD as radiographic abnormalities with new clinical symptoms requiring reoperation. The incidence of ASD would be underestimated as some patients may be not elected in the ASD group.

The most important finding of this research was that the lower lumbar spinal parameter (postoperative LDI) would be a significant risk factor of ASD after L4-S1 PLIF. In most studies, LL has been deeply explored in patients with ASD. Djurasovic et al ${ }^{26}$ reported that patients who developed ASD have significantly less LL. Nakashima et al ${ }^{25}$ concluded that obtaining appropriate LL in PLIF is important for prevention of ASD. $\mathrm{Wu}^{27}$ reported that the postoperative angle of $L L$ was $7.9^{\circ}$ higher than the preoperative angle in patients with degenerative lumbar scoliosis after PLIF. However, few studies focused on construction of LDI influenced by the ratio of LLL and LL. In our study, the angle of LL and LLL increased by $3.96^{\circ}$ and $3.60^{\circ}$ after surgery, respectively. LDI increased by 0.03 postoperatively. Except for postoperative LDI subgroups, we found no significant association between ASD and preLL, preLLL, the value of preLDI, preoperative LDI subgroups, postLL, postLLL and the value of postLDI. 
To the best of our knowledge, this is the first retrospective study to investigate the association between postoperative LDI and ASD after L4-S1 PLIF in which LLL was constant for instrumentation of L4-S1. In a study of 222 patients with degenerative spinal scoliosis, Yilgor et $\mathrm{al}^{16}$ developed a new method of GAP score, in which LDI is a key component, to analyze the spinopelvic alignment and predict the mechanical complications after adult spinal deformity surgery. It has also reported that the integration of relative lumbar lordosis(RLL) and lordosis distribution index (LDI), compared with PI-LL, may contribute to lower rates of mechanical complications and better long-term HRQOL. ${ }^{28}$ Ohba et al ${ }^{29}$ concluded that postoperative LDI is critical to the prevention of excess reciprocal progression of TK resulting in proximal junctional kyphosis. These studies serve as a reminder for us spine surgeons of the role of LDI in spinal biomechanics. In this paper, we clarified the relationship between postoperative LDI and ASD after L4-S1 PLIF. The patients with abnormal postoperative LDI (LDIه0.5, LDIه0.8) were more likely to develop ASD than those with normal postoperative LDI $(0.5 \leq \mathrm{LDI} \leq 0.8)$. The incidence of ASD in low LDI group and high LDI group was $25 \%$ and $18.4 \%$ respectively, significantly higher than that $(4.1 \%)$ in moderate LDI group. Abnormal LDI may alter the physiological distribution of loads and increase biomechanical stress at the level adjacent to the fused segment, leading to accelerated disc degeneration and intervertebral instability. ${ }^{30}$

Although patients with abnormal LDI had lower ASD-free survival than that in patients with normal LDI, low LDI seems to raise more concerns than high LDI according to Kaplan-Meier survivorship analysis. Menezes-Reis et al ${ }^{31}$ reported that hypolordosis of the lumbar spine was associated with a higher frequency of ASD. Postoperative loss of lumbar lordosis has been found to cause excessive mobility and increased biomechanical stress ${ }^{32}$. This in turn causes premature degeneration of the facet joints. As the facet degenerate, translation of the adjacent segment may occur and produce listhesis. This is in accordance with our findings that patients with low LDI were more vulnerable to the disease of ASD.

Our study design had several potential limitations. First, it was a retrospective study which had inherent difficulties in studying ASD. Further prospective studies are needed to validate the relationship between ASD and postoperative LDI. Second, this is a single-center study; hence, the results may not be representative of all patients undergoing L4-S1 PLIF.

\section{Conclusions}

This study investigated the relationship between postoperative LDI and ASD in 200 patients treated with L4-S1 PLIF at an average follow-up of 84 months. BMI is a risk factor for ASD in patients undergoing L4S1 PLIF for degenerative spine diseases. Patients who had abnormal postoperative LDI were statistically more likely to develop ASD than those with normal postoperative LDI. Moreover, patients with low postoperative LDI were at greater risk for developing ASD than those with high postoperative LDI over time, and obtaining appropriate postoperative LDI in L4-S1 PLIF was confirmed to be important for the prevention of ASD. 


\section{List Of Abbreviations}

LDI: Iordosis distribution index; PLIF: posterior lumbar interbody fusion; ASD: adjacent segment disease;

LL: lumbar lordosis; LLL: lower lumbar lordosis;BMI: body mass index

\section{Declarations}

Ethics approval and consent to participate: This study was conducted with approval from the Ethics Committee of Chinese PLA General Hospital. Written informed consent to participate was obtained from all participants.

Consent for publication: We have obtained consent to publish from the participants.

Availability of data and material: The patients' data were collected in the Chinese PLA General Hospital. The datasets used and/or analysed during the current study are available from the corresponding author on reasonable request.

Competing interests: The authors declare that they have no competing interests.

Funding: This study received no specific grant from any funding agency in the public, commercial or notfor-profit sectors.

Authors' contributions: Xuesong Zhang and Yan Wang designed the study. Guoquan Zheng, Chunguo Wang and Tianhao Wang were involved in the manuscript writing. Wenhao Hu, Quanbo ji, Kai Song, Diyu Song and Fanqi Hu collected the clinical data. Zhifa Zhang, Yongyu Hao, Yao Wang, Jing Li and Qingyuan Zheng participated in the statistical analysis, literature search, data interpretation, data monitoring and figure making. Jianrui Li and Surendra K Chaudhary revised the draft. All authors read and approved the final manuscript.

Acknowledgements: not applicable

\section{References}


1. Okuda S, Miyauchi A, Oda T, et al. Surgical complications of posterior lumbar interbody fusion with total facetectomy in 251 patients. J Neurosurg Spine 2006;4:304-9.

2. Okuda S, Oda T, Miyauchi A, et al. Surgical outcomes of posterior lumbar interbody fusion in elderly patients. J Bone Joint Surg Am 2006;88:2714-20.

3. Okuda S, Oda T, Miyauchi A, et al. Surgical outcomes of posterior lumbar interbody fusion in elderly patients. Surgical technique. J Bone Joint Surg Am 2007;89 Suppl 2 Pt.2:310-20.

4. Park P, Garton HJ, Gala VC, et al. Adjacent segment disease after lumbar or lumbosacral fusion: review of the literature. Spine (Phila Pa 1976) 2004;29:1938-44.

5. Lawrence BD, Wang J, Arnold PM, et al. Predicting the risk of adjacent segment pathology after lumbar fusion: a systematic review. Spine (Phila Pa 1976) 2012;37:S123-32.

6. Hambly MF, Wiltse LL, Raghavan N, et al. The transition zone above a lumbosacral fusion. Spine (Phila Pa 1976) 1998;23:1785-92.

7. Virk SS, Niedermeier S, Yu E, et al. Adjacent segment disease. Orthopedics 2014;37:547-55.

8. Xia XP, Chen HL, Cheng HB. Prevalence of adjacent segment degeneration after spine surgery: a systematic review and meta-analysis. Spine (Phila Pa 1976) 2013;38:597-608.

9. Chosa E, Goto K, Totoribe K, et al. Analysis of the effect of lumbar spine fusion on the superior adjacent intervertebral disk in the presence of disk degeneration, using the three-dimensional finite element method. J Spinal Disord Tech 2004;17:134-9.

10. Okuda S, Iwasaki M, Miyauchi A, et al. Risk factors for adjacent segment degeneration after PLIF. Spine (Phila Pa 1976) 2004;29:1535-40.

11. Akamaru T, Kawahara N, Tim Yoon S, et al. Adjacent segment motion after a simulated lumbar fusion in different sagittal alignments: a biomechanical analysis. Spine (Phila Pa 1976) 2003;28:1560-6.

12. Ahn DK, Park HS, Choi DJ, et al. Survival and prognostic analysis of adjacent segments after spinal fusion. Clin Orthop Surg 2010;2:140-7.

13. Ni J, Fang X, Zhong W, et al. Anterior Lumbar Interbody Fusion for Degenerative Discogenic Low Back Pain: Evaluation of L4-S1 Fusion. Medicine (Baltimore) 2015;94:e1851.

14. Bernhardt M, Bridwell $\mathrm{KH}$. Segmental analysis of the sagittal plane alignment of the normal thoracic and lumbar spines and thoracolumbar junction. Spine (Phila Pa 1976) 1989;14:717-21.

15. Barrey C, Roussouly P, Le Huec JC, et al. Compensatory mechanisms contributing to keep the sagittal balance of the spine. Eur Spine J 2013;22 Suppl 6:S834-41.

16. Yilgor C, Sogunmez N, Boissiere L, et al. Global Alignment and Proportion (GAP) Score: Development and Validation of a New Method of Analyzing Spinopelvic Alignment to Predict Mechanical Complications After Adult Spinal Deformity Surgery. J Bone Joint Surg Am 2017;99:1661-72.

17. Pfirrmann CW, Metzdorf A, Zanetti M, et al. Magnetic resonance classification of lumbar intervertebral disc degeneration. Spine (Phila Pa 1976) 2001;26:1873-8. 
18. Kaito T, Hosono N, Mukai Y, et al. Induction of early degeneration of the adjacent segment after posterior lumbar interbody fusion by excessive distraction of lumbar disc space. J Neurosurg Spine 2010;12:671-9.

19. Imagama S, Kawakami N, Matsubara Y, et al. Radiographic Adjacent Segment Degeneration at 5 Years After L4/5 Posterior Lumbar Interbody Fusion With Pedicle Screw Instrumentation: Evaluation by Computed Tomography and Annual Screening With Magnetic Resonance Imaging. Clin Spine Surg 2016;29:E442-E51.

20. Imagama S, Kawakami N, Matsubara Y, et al. Preventive effect of artificial ligamentous stabilization on the upper adjacent segment impairment following posterior lumbar interbody fusion. Spine (Phila Pa 1976) 2009;34:2775-81.

21. Cheh G, Bridwell KH, Lenke LG, et al. Adjacent segment disease followinglumbar/thoracolumbar fusion with pedicle screw instrumentation: a minimum 5-year follow-up. Spine (Phila Pa 1976) 2007;32:2253-7.

22. Radcliff KE, Kepler CK, Jakoi A, et al. Adjacent segment disease in the lumbar spine following different treatment interventions. Spine J 2013;13:1339-49.

23. Liuke $M$, Solovieva $S$, Lamminen $A$, et al. Disc degeneration of the lumbar spine in relation to overweight. Int J Obes (Lond) 2005;29:903-8.

24. Bagheri SR, Alimohammadi E, Zamani Froushani A, et al. Adjacent segment disease after posterior lumbar instrumentation surgery for degenerative disease: Incidence and risk factors. J Orthop Surg (Hong Kong) 2019;27:2309499019842378.

25. Nakashima H, Kawakami N, Tsuji T, et al. Adjacent Segment Disease After Posterior Lumbar Interbody Fusion: Based on Cases With a Minimum of 10 Years of Follow-up. Spine (Phila Pa 1976) 2015;40:E831-41.

26. Djurasovic MO, Carreon LY, Glassman SD, et al. Sagittal alignment as a risk factor for adjacent level degeneration: a case-control study. Orthopedics 2008;31:546.

27. Wu $\mathrm{CH}$, Wong $\mathrm{CB}$, Chen $\mathrm{LH}$, et al. Instrumented posterior lumbar interbody fusion for patients with degenerative lumbar scoliosis. J Spinal Disord Tech 2008;21:310-5.

28. Yilgor C, Sogunmez N, Yavuz Y, et al. Relative lumbar lordosis and lordosis distribution index: individualized pelvic incidence-based proportional parameters that quantify lumbar lordosis more precisely than the concept of pelvic incidence minus lumbar lordosis. Neurosurg Focus 2017;43:E5.

29. Ohba T, Ebata S, Oba H, et al. Correlation Between Postoperative Distribution of Lordosis and Reciprocal Progression of Thoracic Kyphosis and Occurrence of Proximal Junctional Kyphosis Following Surgery for Adult Spinal Deformity. Clin Spine Surg 2018;31:E466-E72.

30. Roussouly P, Nnadi C. Sagittal plane deformity: an overview of interpretation and management. Eur Spine J 2010;19:1824-36.

31. Menezes-Reis R, Bonugli GP, Dalto VF, et al. Association Between Lumbar Spine Sagittal Alignment and L4-L5 Disc Degeneration Among Asymptomatic Young Adults. Spine (Phila Pa 1976) 2016;41:E1081-7. 
32. Oda I, Cunningham BW, Buckley RA, et al. Does spinal kyphotic deformity influence the biomechanical characteristics of the adjacent motion segments? An in vivo animal model. Spine (Phila Pa 1976) 1999;24:2139-46.

\section{Tables}

Table 1. Comparisons of basic characteristics of patients between ASD and Non-ASD group

\begin{tabular}{|c|c|c|c|c|}
\hline & $\operatorname{Total}(n=200)$ & Non-ASD & ASD & $\bar{P}$ \\
\hline Age, years & $64.8 \pm 8.5$ & $64.7 \pm 8.7$ & $66.1 \pm 5.1$ & \multirow{2}{*}{$\begin{array}{l}0.315 \\
0.773\end{array}$} \\
\hline $\begin{array}{l}\text { Sex, n (\%) } \\
\text { Male }\end{array}$ & & $82(448)$ & & \\
\hline Female & $111(55.5)$ & $101(55.2)$ & $10(58.8)$ & \multirow{4}{*}{$\begin{array}{r}\square 0.001 \\
0.001\end{array}$} \\
\hline BMI & $24.14 \pm 3.42$ & $23.87 \pm 3.33$ & $27.04 \pm 3.00$ & \\
\hline BMI group, n(\%) & & & & \\
\hline ВMI $25 \mathrm{~kg} / \mathrm{m}^{2}$ & $121(60.5)$ & $117(63.9)$ & $4(23.5)$ & \\
\hline $\mathrm{BMI} \geq 25 \mathrm{~kg} / \mathrm{m}^{2}$ & 79 (39.5) & $66(36.1)$ & $13(76.5)$ & \\
\hline Comorbidities, n (\%) & $131(65.5)$ & $119(65.0)$ & $12(70.6)$ & 0.645 \\
\hline Hyperter & & & & \\
\hline Diabetes Mellitus & $57(28.5)$ & $51(27.9)$ & $6(35.3)$ & 0.713 \\
\hline Coronary artery disease & $97(48.5)$ & $90(49.2)$ & $7(41.2)$ & 0.528 \\
\hline Hospital Stay (days) & $9.0(7.0 \square 11.0)$ & $9.0(7.0 \square 11.0)$ & $\begin{array}{l}5(29.4) \\
8.0(6.0 \square\end{array}$ & $\begin{array}{l}0.448 \\
0.757\end{array}$ \\
\hline Follow-up period (months) & 84.0 & 85.0 & $62.8 \pm 24.6$ & $\square 0.001$ \\
\hline & & & & \\
\hline $\begin{array}{c}\text { Intraoperative blood } \\
\text { loss (ml) }\end{array}$ & $290(220 \square 380)$ & $290(220 \square 380)$ & $294.7 \pm 111.0$ & 0.920 \\
\hline Operation time (hours) & $\begin{array}{c}4.45(3.70 \square \\
5.30)\end{array}$ & $\begin{array}{c}4.50(3.70 \square \\
5.30) \\
\end{array}$ & $4.35 \pm 0.87$ & 0.525 \\
\hline
\end{tabular}

Mann-Whitney U test, Pearson $\chi 2$ test, independent-samples t test

Abbreviation: ASD, adjacent segment disease; BMI, body mass index; COPD, chronic obstructive pulmonary disease

Table 2.Changes in pre and postoperative radiographic parameters

\begin{tabular}{lccc}
\hline Radiographic Parameters & Pre Op & Post Op & P \\
\hline Lumbar Lordosis $\left({ }^{\circ}\right)$ & $38.71 \pm 6.96$ & $42.67 \pm 8.51$ & 00.001 \\
Lower Lumbar Lordosis $\left({ }^{\circ}\right)$ & $25.22 \pm 4.82$ & $28.82 \pm 5.90$ & $\square 0.001$ \\
Lordosis Distribution Index & $0.66 \pm 0.10$ & $0.69 \pm 0.13$ & .004 \\
\hline
\end{tabular}

Paired-samples t test

'able 3. Comparisons of lower lumbar spinal parameters and LDI in the different groups 


\begin{tabular}{|c|c|c|c|c|}
\hline & Total & ASD & Non-ASD & $\mathbf{P}$ \\
\hline Pre LL $\left(^{\circ}\right)$ & $38.71 \pm 6.96$ & $37.17 \pm 7.31$ & $38.85 \pm 6.93$ & 0.341 \\
\hline Pre LLL $\left(^{\circ}\right)$ & $25.22 \pm 4.82$ & $23.71 \pm 4.55$ & $25.36 \pm 4.83$ & 0.177 \\
\hline Pre LDI & $0.66(0.60-0.71)$ & $0.65 \pm 0.11$ & $0.66(0.60-0.71)$ & 0.682 \\
\hline Pre LDI Group (Low LDI & Moderate LDI, H & $\operatorname{igh}$ LDI),n(\%) & & 0.252 \\
\hline Low LDI 0.5 & $13(6.5)$ & $2(11.8)$ & $11(6.0)$ & \\
\hline $0.5 \leq$ Moderate LDI $\leq 0.8$ & $172(86.0)$ & $13(76.4)$ & $159(86.9)$ & \\
\hline High LDI $\square 0.8$ & $15(7.5)$ & $2(11.8)$ & $13(7.1)$ & \\
\hline \multicolumn{4}{|c|}{ Pre LDI Group ( Normal LDI, Abnormal LDI ) n(\%) } & 0.267 \\
\hline $0.5 \leq$ Normal $\mathrm{LDI} \leq 0.8$ & $172(86.0)$ & $13(76.5)$ & 159 (86.9) & \\
\hline Abnormal LDI $(\square 0.5, \square 0.8)$ & $36(14.0)$ & $4(23.5)$ & $24(13.1)$ & \\
\hline Post LL $\left({ }^{\circ}\right)$ & 42.6 & $40.35 \pm 7.96$ & 42. & 0.241 \\
\hline Post LLL $\left({ }^{\circ}\right)$ & $28.82 \pm 5.90$ & $27.69 \pm 5.68$ & $28.93 \pm 5.93$ & 0.410 \\
\hline Post LDI & $0.69 \pm 0.13$ & $0.71 \pm 0.19$ & $0.68 \pm 0.12$ & 0.578 \\
\hline \multicolumn{4}{|c|}{ Post LDI Group (Low LDI, Moderate LDI, High LDI),n(\%) } & 0.001 \\
\hline Low LDI $\square .5$ & $16(8.0)$ & $4(23.5)$ & $12(6.6)$ & \\
\hline $0.5 \leq$ Moderate LDI $\leq 0.8$ & $146(73.0)$ & $6(35.3)$ & $140(76.5)$ & \\
\hline High LDI $\square 0.8$ & $38(19.0)$ & $7(41.2)$ & $31(16.9)$ & \\
\hline \multicolumn{4}{|c|}{ Post LDI Group (Normal LDI, Abnormal LDI) n(\%) } & 0.001 \\
\hline $0.5 \leq$ Normal LDI $\leq 0.8$ & $146(73.0)$ & $6(35.3)$ & 140 & \\
\hline Abnormal LDI(৫0.5,৫0.8) & $54(27.0)$ & $11(64.7)$ & 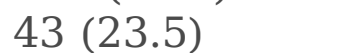 & \\
\hline
\end{tabular}

.dependent-samples t tests, Mann-Whitney U test, Pearson $\chi 2$ test, Fisher's exact test

bbreviation: ASD, Adjacent Segment Disease; LL, Lumbar Lordosis; LLL, Lower Lumbar ordosis; LDI, Lordosis Distribution Index

Table 4. Comparisons of incidence of ASD among different postoperative LDI groups.

\begin{tabular}{ccccc}
\hline & Total (n) & Non-ASD & ASD & P \\
\hline Low LDI, n(\%) & 16 & $12(75)$ & $4(25)$ & .006 \\
Moderate LDI, n(\%) & 146 & $140(95.9)$ & $6(4.1)$ & \\
Low LDI, n(\%) & 16 & $12(75)$ & $4(25)$ & .859 \\
High LDI, n(\%) & 38 & $31(81.6)$ & $7(18.4)$ & \\
Moderate LDI, n(\%) & 146 & $140(95.9)$ & $6(4.1)$ & .007 \\
High LDI, n(\%) & 38 & $31(81.6)$ & $7(18.4)$ & \\
\hline
\end{tabular}

Abbreviation: ASD, Adjacent Segment Disease; LDI, Lordosis Distribution Index

\section{Figures}




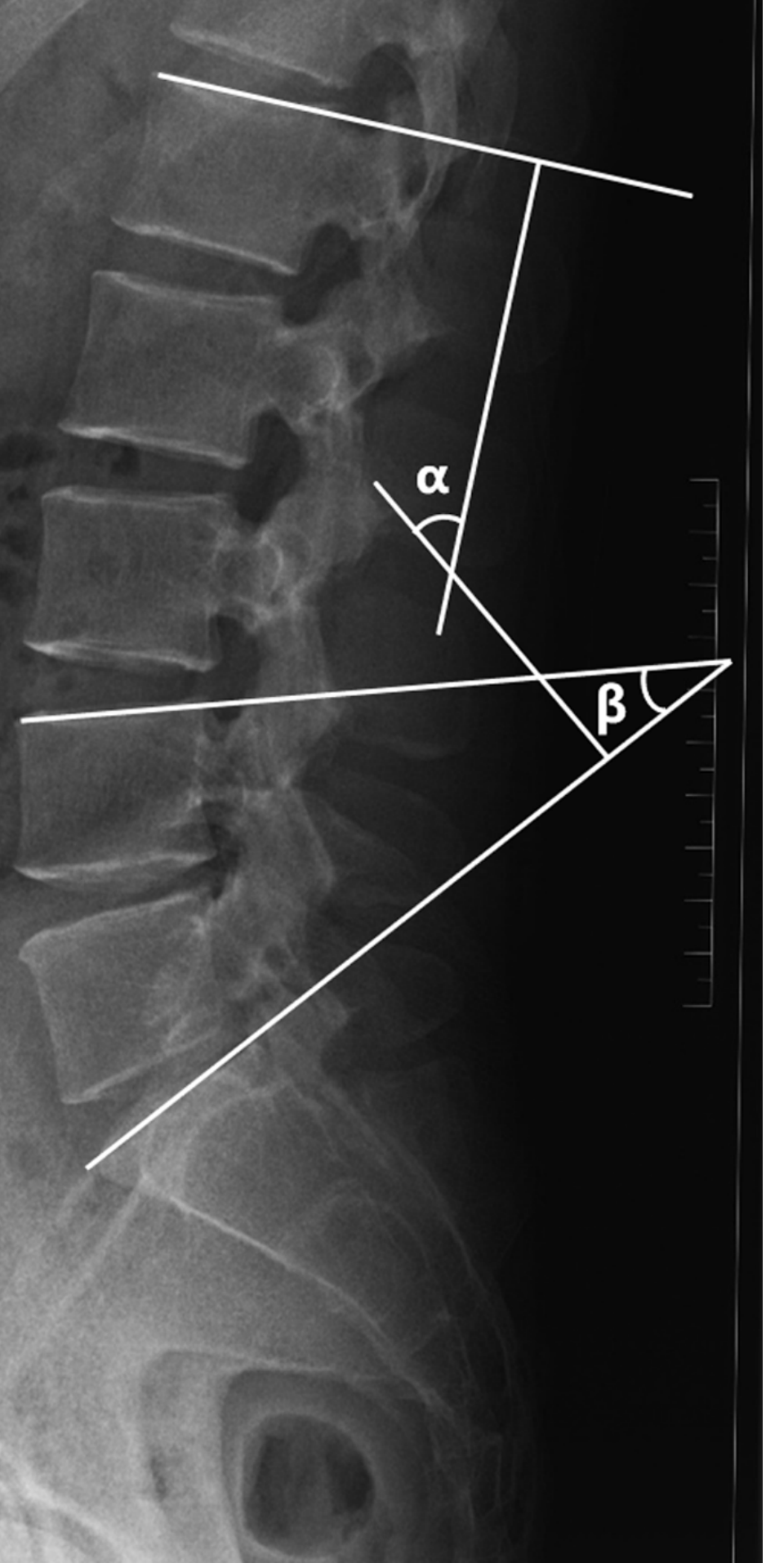

Figure 1

Measurement of lower lumbar spinal parameters. LL(a) is the angle between the superior endplate of L-1 and S-1. $\operatorname{LLL}(\beta)$ is the angle between the superior endplate of $L 4$ and S1. LDI equals to $\beta / \alpha \times 100 \%$. 


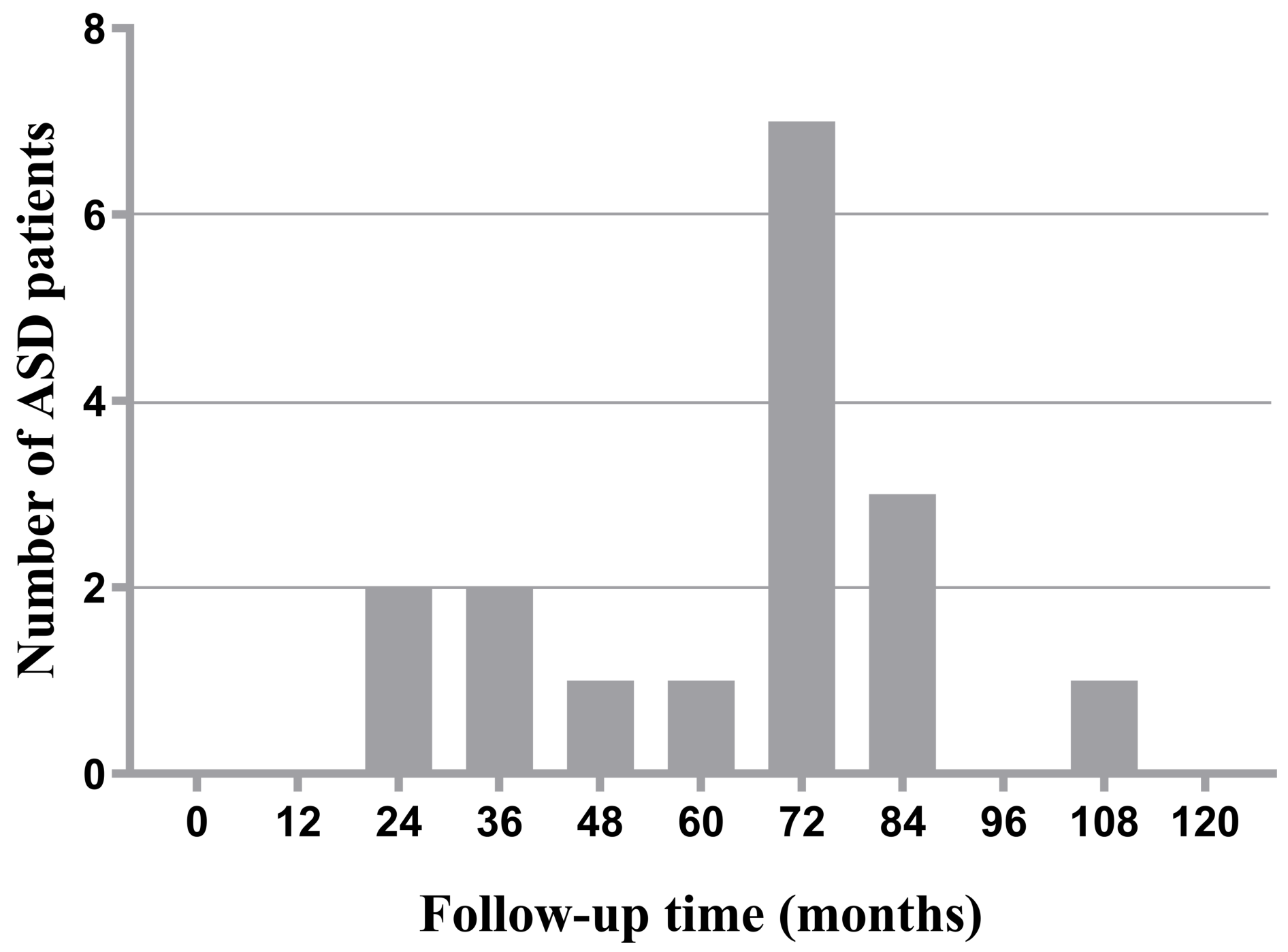

Figure 2

Frequency distribution of follow-up time of adjacent segment disease (ASD囚patients after L4-S1 posterior lumbar interbody fusion. 

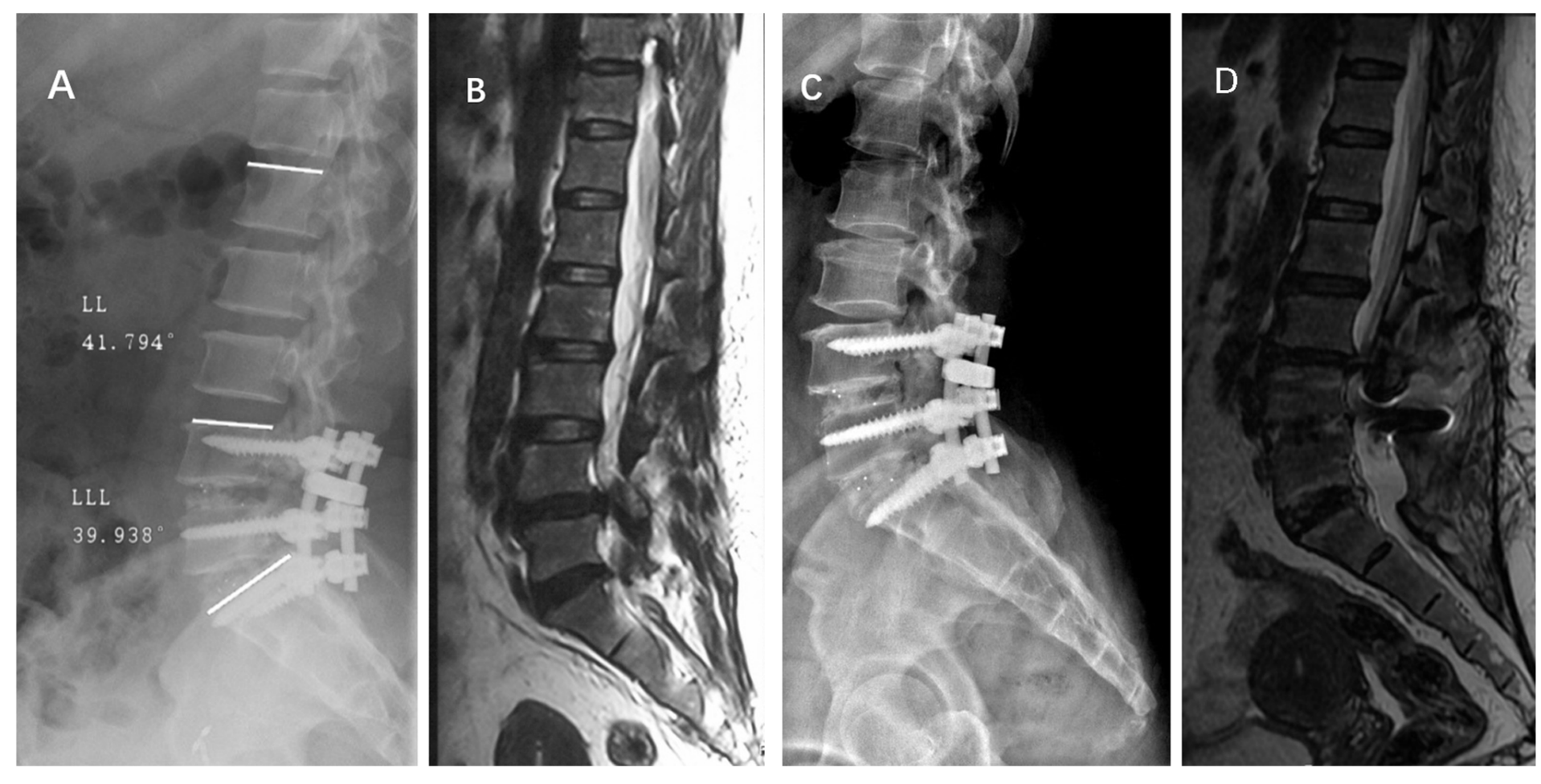

\section{Figure 3}

Imaging studies of ASD associated with high postoperative LDI. A, a 47-year-old female patient underwent L4-S1 PLIF with the postoperative LL of $41.79^{\circ}$ and LLL of $39.94^{\circ}$. The ultimate LDI equals to 95.57\%. B, preoperative sagittal T2-weighted MRI scans at the L3-4 showing no or mild spinal stenosis (Imagama's Classification II) and disc degeneration of Pfirrmann Classification III. C, postoperative neutral lateral X-ray obtained 69 months after surgery revealing retrolisthesis of L3 vertebra. D, the final follow-up MRI scans demonstrating severe spinal stenosis(Imagama's Classification IV) and disc degeneration of Pfirrmann Classification IV 


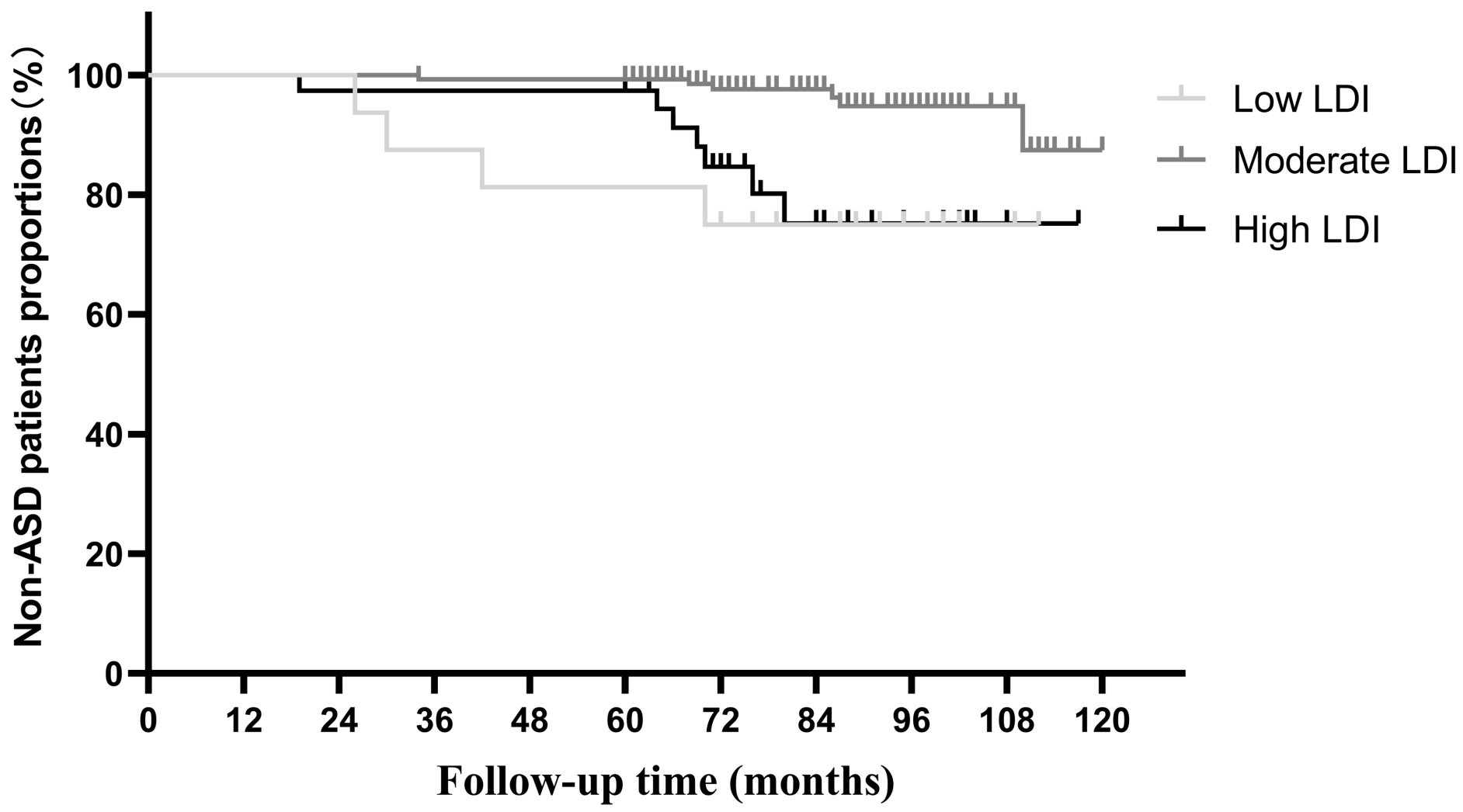

Figure 4

Kaplan-Meier analysis of adjacent segment disease (ASD) patients after L4-S1 posterior lumbar interbody fusion during the 120 months of follow-up period by three kinds of lordosis distribution index (LDI) groups. (Log Rank test, $\mathrm{P}=0.001$ ) 